\title{
Effect of Temperature on the $I-V$ Characteristics of a Polycrystalline Solar Cell
}

\author{
Indra Bahadur Karki \\ Department of Physics, Patan Multiple Campus, Tribhuvan University, Nepal \\ Correspondence to: indrakarky@gmail.com
}

\begin{abstract}
The present paper reports the temperature dependencies of full-spectrum photovoltaic parameters for polycrystalline PV module. The measurements were performed under outdoor environment conditions. The most interesting feature that was observed for these devices was that above a celltemperature of $20^{\circ} \mathrm{C}$ the positive temperature coefficient observed for the short-circuit currentexceeds in magnitude the negative temperature coefficient that was found for the open-circuitvoltage. This means that, unlike the situation for conventional $P V$ devices, these cells actually exhibit decrease in efficiency with increasing temperature (reaching a value of $0.05 \%$ at $60^{\circ} \mathrm{C}$ ).
\end{abstract}

Keywords: Photovoltaic, Temperature coefficient, polycrystalline solar cell, conversion efficiency.

\section{Introduction}

Today, the photovoltaic (PV) cells is one of the fastest growing renewable energy technologies and it is expected that it will play a major role in the future global electricity generation [IRENA, 2012]. Solar PV systems are also one of the most "democratic" renewable technologies, in that their modular size means that they are within the reach of individuals, co-operatives and small businesses who want to access their own generation and lock-in electricity prices [IRENA, 2012].

PV solar panels are composed of solar cells. A solar cell is an electrical device that converts the energy of light directly into electricity (DC) by the photovoltaic effect. Solar cells created with silicon seem to be the most widely used today, but many companies and scientists have been in the lab trying to concoct a more efficient cell, and ultimately, solar panel system The basic material used for production of the solar cells is silicon. Solar Cell is a device that converts light directly into DC (direct current) electricity. Solar Cell can be distinguish in three cell types according to the type of crystal i.e., monocrystalline, polycrystalline and amorphous. To produce a monocrystalline silicon cell, absolutely pure semiconducting material is necessary. The production of polycrystalline cells is more cost-efficient and it has grain boundaries, which are randomly oriented, visible on the active surface. There are three main types of solar cells: Monocrystalline, Polycrystalline and thin film or amorphous. Monocrystalline solar cells are formed on the silicon crystal with a homogeneous structure. The basis for the formation of cells is suitable size blocks of silicon. The blocks are cut into a wafer whose thickness is about $0.3 \mathrm{~mm}$. Monocrystalline solar cells achieve the highest levels of performance and life [Breyer and 
Gerlach, 2011 and Wacáawek and Rodziewicz 2011]. Polycrystalline cells consist of many small silicon grains. These solar cells are less efficient than monocrystalline. The production process is easier and have less expensive [Wacáawek and Rodziewicz, 2011; Rodacki and Kandyba, 2000]. Amorphous type (thin film) solar cells are produced by embedding few layers of silicon on the surface of another material, such as a glass. In these solar cells, we cannot distinguish individual cells. Amorphous solar cells are usually used in small devices such as calculators and watches [Klugmann, 2008].

All solar module parameters, including short-circuit current, open-circuit voltage, fill factor, efficiency and impact of series and parallel resistances are changed due to changing the light intensity and temperature [Luque and Hegedus, 2003]. Therefore, it is important to study the effect of the light intensity and temperature on the output performance of the solar module.

Temperature affects how electricity flows through an electrical circuit by changing the speed at which the electrons travel. This is due to an increase in resistance of the circuit that results from an increase in temperature. Likewise, resistance decreases with decreasing temperatures.

In this work, a detailed experimental investigation of module PV parameters with light intensity and temperature were studied.

\subsection{Photovoltaic mechanism in p-n junctions}

When the $\mathrm{p}-\mathrm{n}$ junction is hit by a light beam, photon with energy greater when semiconductors energy hole generates electron-hole pairs. The newly created electric charge carriers are mostly recombined, which generates heat. The condition for the creation of the photovoltaic phenomenon is to separate these pairs before recombination. This requires a presence of aninternal electric field. This strong electric field exists in the p-n junction due to spatial cargo. Inthis electric field the electrons are moved from p-type to n-type semiconductors and holes aremoved from the n-type semiconductor to p-type, resulting in separation of generated electronholepairs. Separated minority carriers on the one side of the connector, are becoming majoritycarriers with limitless lifetime on the other side, thus they create voltage (Vsc) and current (Isc) ofa solar cell [Green, 1981].Current-voltage characteristics of the cell are a graph of the output current of the PV generator asa function of voltage at a given temperature and irradiance.

\subsection{Principles}

The classic definition of the temperature coefficient for a parameter relates to the change in that parameter when only temperature is varied, other factors that might influence the parameter being held constant. Temperature coefficients for Isc, Ipp, Voc, Vpp, Pmax, $\mathrm{FF}$, and $\eta$ can all be determined for given photovoltaic modules.

Regression analysis is used to determine temperature coefficient parameters for Isc, Ipp, Voc, Vpp,Pmaxand FF. The energy conversion efficiency $\eta$ of modules is defined by:

$$
\eta=\text { Pout } / \text { Pin }=\text { IppVpp } / \text { Pin }=\text { FFVocIsc } / \text { Pin, }
$$


where Pin is the total radiative input power of all light incident on the cell/module, and Pout is theelectrical power output of the cell/module. The fill factor, FF is defined by:

$$
\mathrm{FF}=(\mathrm{Ipp} * \mathrm{Vpp} / \mathrm{Isc} * \mathrm{Voc}) * 100 \%
$$

The fill factor measures how square the $I-V$ curve. The higher the FF the more power the cell produces. The relation between shortcircuit current and open- circuit voltage is given by [Green, 1981].

$\mathrm{I}_{\mathrm{sc}}=\mathrm{I}_{0}\left(\mathrm{e}_{\mathrm{q}} \mathrm{V}_{\mathrm{oc}} / \mathrm{AkT}-1\right)$ and, $\mathrm{Voc}=(\mathrm{AkT} / \mathrm{q}) \ln (\mathrm{Isc} / \mathrm{I} 0+1)$

Where Isc $=$ short circuit current (the current at $\mathrm{V}=0$. Ideally this is equal to the light generated current (IL). Voc $=$ open circuit voltage (the voltage at $\mathrm{I}=0$, Voc depends strongly on the properties of the semiconductor by virtue of its dependence on dark current $\mathrm{I}_{0}$. $\mathrm{k}$ $=$ Boltzmann constant, $\mathrm{T}=$ temperature of cell, $\mathrm{q}=$ electronic charge, $\mathrm{A}=$ diode quality factor of p-n junction. The temperature dependence of Vocis given by [Green, 1981].

$$
\mathrm{dVoc} / \mathrm{dT}=-(\mathrm{Eg} / \mathrm{q}-\mathrm{Voc}+3 \mathrm{kT} / \mathrm{q}) / \mathrm{T}
$$

Where $\mathrm{Eg}=$ band gap energy; and $\mathrm{T}=$ Kelvin temperature of cell.The area of PVpolycrystalline solar module $(\mathrm{S} \times 45)($ Cells $=36)$ was $0.4 \mathrm{~m}^{2}$.

\section{Methodology}

At first, PV modules were cooled to lower its temperature to below the ambient temperature before experiment (ideally less than $10{ }^{\circ} \mathrm{C}$ ). The experiments were performed during an approximately half hour period around solar noon on a cloudless, clear day.
This ensured that the insolation were constant to within about $1 \%$. The PV module was placed on a stand at normal incidence to the incoming radiation. Two pyranometers (PSP and $\mathrm{Li}$-cor) were placed on the stand, in the same plane as the PV module aperture. Thermocouples were taped to module's rear surface to measure all temperatures and the rear surfaces of modules were insulated as shown in Figure 1. Data were stored in the Campbell data logger. Each cooled module's current-voltage $(I-V)$ curve was measured repeatedly using a Daystar $I-V$ curve tracer over a range of temperatures, roughly from $10{ }^{\circ} \mathrm{C}$ to Stagnation temperature (50 to 75 $\left.{ }^{0} \mathrm{C}\right)$.

The following measuring equipments were used to study the photovoltaic parameters in outdoor experiments.

1. I-V curve tracer (A Daystar Corp.)

2. Two calibrated pyranometers (EppleyCorp. PSP and Li-cor).

3. A Solarex Corp.SX45 module (standard references modules)

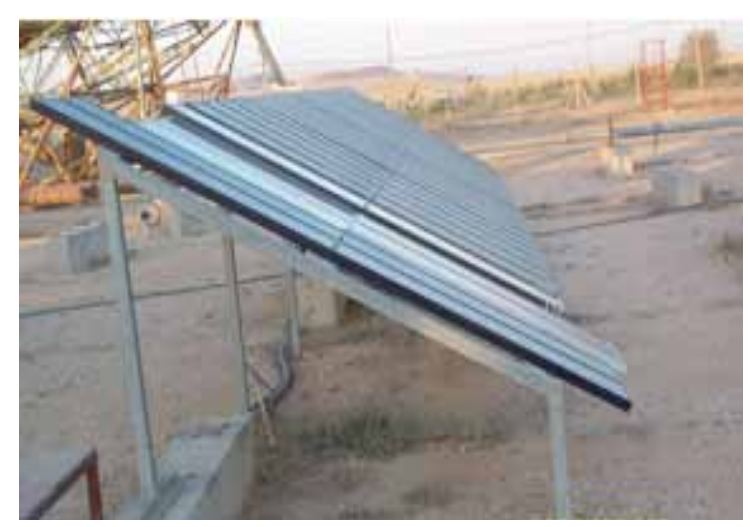

Figure 1. Outdoor experiment of crystalline solar PV module. 
4. Copper-Constantine thermocouples.

5. Datalogger (ACampbell Scientific Corp.21X) for recording irradiance and temperatures.

6. A laptop computer for downloading data from the $I-V$ curve tracer and the data logger.

7. Polycrystalline PV- module (SX-45).

\section{For $1000 \mathrm{~W} / \mathrm{m}^{2}$;}

$\mathrm{I}_{\mathrm{sc}}{ }^{1000}=\mathrm{Isc} /$ Irradiance* $* 1000$;

$\mathrm{I}_{\mathrm{pp}}{ }^{1000}=\mathrm{Ipp} /$ Irradiance*1000;

$\mathrm{P}_{\max }{ }^{1000}=\mathrm{Pmax} /$ Irradiance* 1000 .

For STC $\left(1000 \mathrm{~W} / \mathrm{m}^{2}, \mathbf{2 5}^{\circ} \mathrm{C}\right)$ :

$\mathrm{I}_{\mathrm{sc}}(\mathrm{STC})=\mathrm{I}_{\mathrm{sc}} 1000-\left[\alpha \mathrm{I}_{\mathrm{sc}}\left(\mathrm{T}_{\mathrm{mod}}-25\right)\right] ; \mathrm{I}_{\mathrm{pp}}(\mathrm{STC})$

$=\mathrm{I}_{\mathrm{pp}} 1000-\left[\alpha\left(\mathrm{I}_{\mathrm{pp}}\right)\left(\mathrm{T}_{\bmod }-25\right)\right]$;

$\mathrm{V}_{\mathrm{oc}}(\mathrm{STC})=\mathrm{V}_{\mathrm{oc}}-\left[\beta \mathrm{V}_{\mathrm{oc}}\left(\mathrm{T}_{\bmod }-25\right)\right] ; \mathrm{V}_{\mathrm{pp}}(\mathrm{STC})$

$=\mathrm{Vpp}-\left[\beta \mathrm{V}_{\mathrm{pp}}\left(\mathrm{T}_{\bmod }-25\right)\right]$;

$\mathrm{P}_{\max }(\mathrm{STC})=\mathrm{I}_{\mathrm{pp}}(\mathrm{STC}) * \mathrm{~V}_{\mathrm{pp}}(\mathrm{STC})$

$=\mathrm{P}_{\max } 1000-\left[\gamma\left(\mathrm{T}_{\bmod }-25\right)\right]$;

Efficiency $(\eta)=\left(I_{p p} * V_{p p} /\right.$ Irradiance*Area $) * 100 \%$; Fill factor $(\mathrm{FF})=\left(\mathrm{I}_{\mathrm{pp}} * \mathrm{Vpp} / \mathrm{I}_{\mathrm{sc}} * \mathrm{Voc}\right) * 100 \%[$ King et al., 2004].

\section{Results and Discussion}

Figure 2 and 3 show that the variation of the current and voltage parameters with module temperature. It has been found that current parameters of each module increase with increasing temperature but voltage parameters of each module decrease with increasing temperature. About $9.8 \%$ and $12 \%$ decrement in Vocand Vpp, respectively has been observed. It can be noted from the results that the temperature has a crucial impact on voltage parameters of solar module rather than the current parameters [Radziemska, 2003]. Figure 4 shows power graph versus module temperature. It has been found that the power of each module demonstrated a decrease with temperature.

The dependence of fill factor with temperature for each module was shown in Figure 5.We found that the fill factor of each module also demonstrated a decrease with temperature increases [Cuce et al., 2013]. The dependence of efficiency with temperature for each module is shown in Figure 6. We found that the conversion efficiency of each module demonstrated a decrease with temperature [Cuce et al. 2013]. Open circuit voltage $\left(\mathrm{V}_{\mathrm{OC}}\right)$ at the terminals of unloaded (open) PV generator at a given temperature and irradiance, Short circuit current $\left(\mathrm{I}_{\mathrm{SC}}\right)$ - the output current photovoltaic generative at a given temperature and irradiance, PMPP - Point MPP (Maximum Power Point) is a point whose coordinates $\mathrm{V}_{\mathrm{MPP}} \times \mathrm{I}_{\mathrm{MPP}}$ and form a rectangular shape with the largest possible area under the curve $I-V$. Voltage generated by a single photovoltaic cell depends on the type of material from which it was produced and is about $0.6 \mathrm{~V}$.

The output voltage is weakly dependent on the intensity of the radiation, while the current increases significantly with an increase in radiation intensity [Green, 1981 and Radziemska, 2003]. Position of the operating point is strongly dependent on the resistance and radiation. The output voltage depends significantly on the temperature of solar cells: increased results are in a lower working temperature and efficiency [Green, 1981]. 


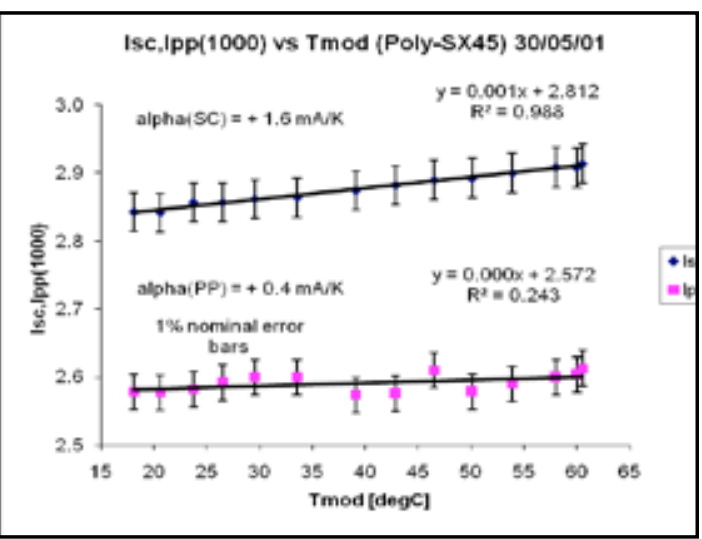

Figure 2. Short circuit and peak current graphs versus module temperature.

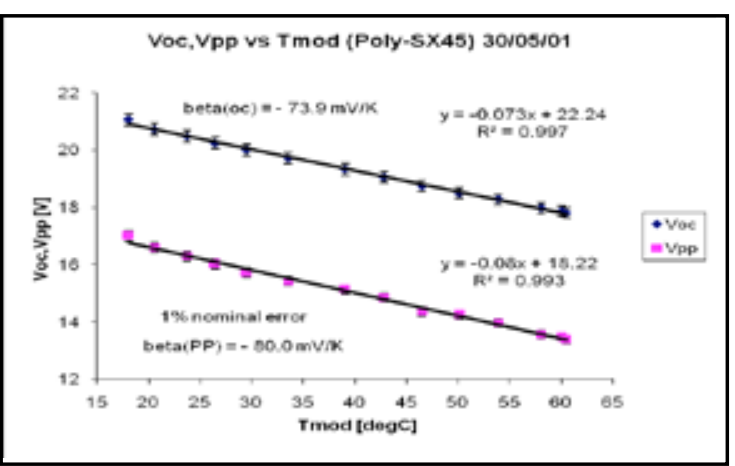

Figure 3. Open circuit and peak voltage graphs versus module temperature.

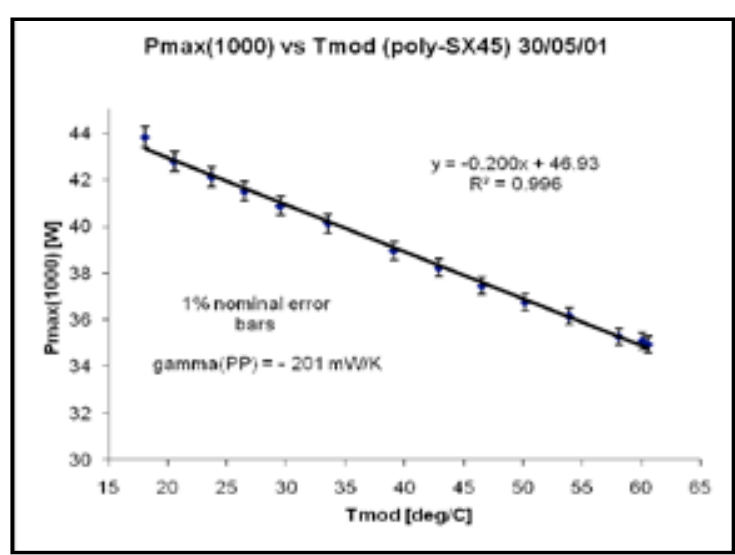

Figure 4. Maximum power graphs versus module temperature.

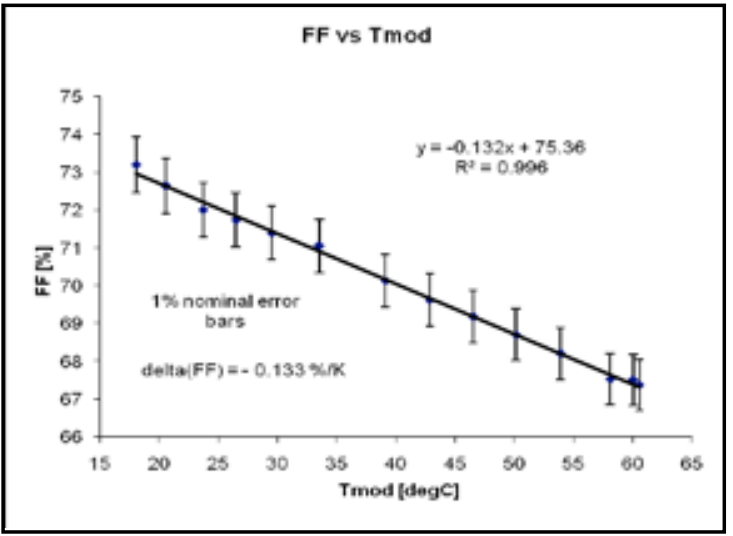

Figure 5. Fill factor graphs versus module temperature.

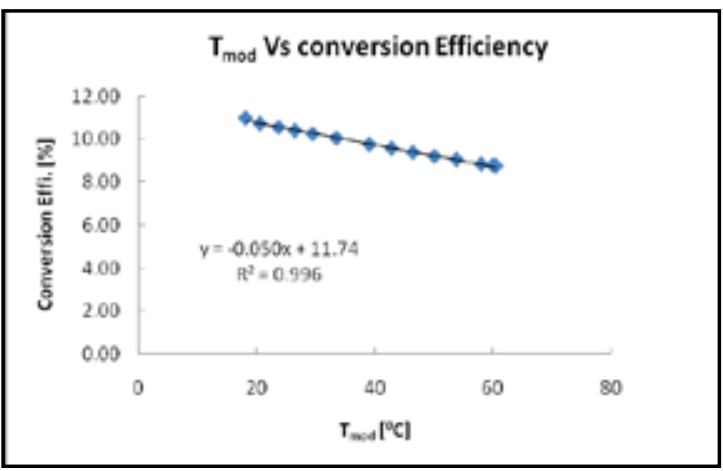

Figure 6. Efficiency graphs versus module temperature of the modules under investigation

Because the current and voltage output of a PV panel is affected by changing weather conditions, it is important to characterize the response of the system to these changes so the equipment associated with the PV panel can be sized appropriately. The average operating voltage and current of a PV system is important to consider for safety concerns, equipment capabilities and choices, and minimizing the amount of wire required for construction. Using temperature and solar irradiation data, engineers and physicists can estimate and design how much energy a PV power plant might generate over its lifetime. 


\section{Conclusion}

In this paper, the temperature dependency of output performance parameters of polycrystalline silicon solar modules has been experimentally investigated. The results of the various modules indicated that light intensity has a dominant effect on current parameters. Short circuit current and maximum current are increase linearly with increasing light intensity. Temperature canaffect how electricity flows through an electrical circuit by changing the speed at which theelectrons travel. Also, since solar panels work best at certain weather and temperature conditions, engineers design ways to improve the efficiency of solar panels that operate in non-optimaltemperature conditions.

We observed that module temperature has a dramatic effect on voltage parameters. Open circuit voltage and maximum voltage are decrease with increasing module temperature. So, the maximum output power density decreased by $17 \%$ for poly-crystalline silicon with increasing module temperature from 15 ${ }^{\circ} \mathrm{C}$ to $60{ }^{\circ} \mathrm{C}$. The band gap of solar cell, $\mathrm{Eg}=$ $1.09 \mathrm{eV}$ was found from calculations using the measured values of current and voltages.

\section{Acknowledgments}

The author would like to acknowledge Prof. Dr. David Faiman, Sedeboker Campus, Ben-Gurion University, Israel for research guidance and support. Author is also thankful to Bona-Tera foundation, Israel for fellowship to carry out the research work. Editor N. P. Chapagain thanks the reviewers for their assistance in evaluating this paper.

\section{References}

Breyer, C. and Gerlach A. (2011), Global Overview on Grid-Parity Event Dynamics, Proceedings of the 26th European Photovoltaic Solar Energy Conference, 5 - 9th September, Hamburg.

Cuce E., Cuce P. and Bali T. (2013), An experimental analysis of light intensity and temperature dependency of photovoltaic module parameters. Applied Energy, 111, 374-382.

Green M. A. (1981), Solar Cells: Operating Principles, Technology, and System Applications, Prentice-Hall series, Australia.

International Renewable Energy Agency (IRENA) (2012), Renewable Energy Technologies:

Cost Analysis Series, Solar Photovoltaics, 1, 4-5.

King D.L., Boyson W.E. and Kratochvill J.A.(2004), Photovoltaic Array Performance Model, SANDIA REPORT-2004, Sandia National Laboratories, Albuquerque, New Mexico 87185.

Klugmann R. E. (2008), Breaking the stereotype -Photovoltaic not for us, Crystal Energies, 6, 1012.

Luque A. and Hegedus S. (2003), Handbook of Photovoltaic Science and Engineering, John Wiley and Sons Publication, NJ 07030, U.S.A.

Radziemska E. (2003), The effect of temperature on the power drop in crystalline silicon solar cells. Renew. Energy, 28, 1-12.

Rodacki, T. and Kandyba A. (2000), Energy conversion in solar power, Energy conversion in solar power station, monograph, Silesian University of Technology Publication, Gliwice, (in Polish).

Wacáawek, M. and Rodziewicz T. (2011), Solar cells: the impact of the environment on their work, Publishing House WNT, Warsaw. 